Abstract PTU-034 Table 1 Indications and associated complications for ERCP in different age groups (\% in brackets)

\begin{tabular}{|c|c|c|c|c|c|c|c|}
\hline Age Group/Indication & Gallstones & Ca Pancreas & Stricture unspecified & Cholangio & Post Pancreatitis & Other & Not documented \\
\hline$A$ & $\begin{array}{l}\text { AB33 } \\
(70.2)\end{array}$ & $\begin{array}{l}\text { AB7 } \\
(14.9)\end{array}$ & $\begin{array}{l}\text { AB2 } \\
(4.3)\end{array}$ & $\begin{array}{l}\text { ABO } \\
\text { (0) }\end{array}$ & $\begin{array}{l}A B 1 \\
(2.1)\end{array}$ & $\begin{array}{l}\mathrm{AB} 1 \\
(2.1)\end{array}$ & $\begin{array}{l}\text { AB3 } \\
(6.4)\end{array}$ \\
\hline B & $\begin{array}{l}\text { AB101 } \\
(67.3)\end{array}$ & $\begin{array}{l}\text { AB19 } \\
(12.7)\end{array}$ & $\begin{array}{l}\text { AB4 } \\
(2.7)\end{array}$ & $\begin{array}{l}\text { AB5 } \\
(3.3)\end{array}$ & $\begin{array}{l}A B 1 \\
(0.7)\end{array}$ & $\begin{array}{l}\mathrm{AB} 13 \\
(8.7)\end{array}$ & $\begin{array}{l}\text { AB7 } \\
(4.7)\end{array}$ \\
\hline Total & $\begin{array}{l}A B 134 \\
(68.0)\end{array}$ & $\begin{array}{l}\text { AB26 } \\
(13.2)\end{array}$ & $\begin{array}{l}\text { AB6 } \\
(3.0)\end{array}$ & $\begin{array}{l}\text { AB5 } \\
(2.5)\end{array}$ & $\begin{array}{l}A B 2 \\
(1.0)\end{array}$ & $\begin{array}{l}\text { AB14 } \\
(7.1)\end{array}$ & $\begin{array}{l}\text { AB10 } \\
(5.1)\end{array}$ \\
\hline Age Group/Complication & Bleeding & Pancreatitis & Biliary sepsis & Perforation & Other & Totals & \\
\hline$A$ & $\begin{array}{l}A B 1 \\
(12.5)\end{array}$ & $\begin{array}{l}\text { AB1 } \\
(12.5)\end{array}$ & $\begin{array}{l}A B 1 \\
(12.5)\end{array}$ & $\begin{array}{l}A B 0 \\
(0)\end{array}$ & $\begin{array}{l}\text { AB5 } \\
(62.5)\end{array}$ & 8 & \\
\hline B & $\begin{array}{l}\text { AB3 } \\
(15)\end{array}$ & $\begin{array}{l}A B 6 \\
(30)\end{array}$ & $\begin{array}{l}\text { AB4 } \\
(20)\end{array}$ & $\begin{array}{l}A B 1 \\
(5)\end{array}$ & $\begin{array}{l}A B 6 \\
(30)\end{array}$ & 20 & \\
\hline Total & $\begin{array}{l}\text { AB4 } \\
(14.3)\end{array}$ & $\begin{array}{l}A B 7 \\
(25)\end{array}$ & $\begin{array}{l}\text { AB5 } \\
(17.9)\end{array}$ & $\begin{array}{l}\text { AB1 } \\
(3.6)\end{array}$ & $\begin{array}{l}\text { AB11 } \\
(39.3)\end{array}$ & 28 & \\
\hline
\end{tabular}

1."C Smith, ' J M Thompson, 'B Vijayan, 'A Fraser, 'E M El-Omar, ' IJ S Leeds. 'Department of Gastroenterology, Aberdeen Royal Infirmary, Aberdeen, UK

Introduction Lower gastrointestinal bleeding (LGIB) is a common and heterogeneous condition, in which there is a paucity of data concerning predictors of adverse outcomes. This study aimed to identify independent risk factors for adverse outcomes in LGIB, and derive prognostic scoring systems to stratify patients by risk on admission.

Methods The Aberdeen bleeding unit opened in 1991 and has recorded demographics, presenting features, haemodynamic status and outcomes on all admissions in a comprehensive database. Analysis was performed on admissions due to LGIB over the period 1991 to 2005. Independent risk factors for re-bleeding, requirement for surgical intervention, and mortality at 30 days were elucidated by means of univariate and multivariate binary logistic regression analyses. Risk factors were then modelled into simple numerical prognostic scoring systems which underwent preliminary validation tests in order to determine their predictive performance using receiver operating curve analysis.

Results Over the study period, 2385 patients were admitted with LGIB. Re-bleeding was experienced in 322 (13.5\%), $135(5.7 \%)$ required surgery and $129(5.6 \%)$ died within 30 days of admission. Multivariate analysis revealed that re-bleeding was associated with inpatient status at the time of initial bleed (OR 1.8; 95\% CIs 1.32.5 ), age 60-79 (OR 1.5; 95\% CIs 1.0-2.3), age > 80 (OR 2.1; 95\% CIs 1.3-3.2), syncope (OR 2.3; 95\% CIs 1.5-3.6), underlying malignancy (OR 2.1; 95\% CIs 1.0-4.3), hypotension (OR 2.3; 95\% CIs 1.4-3.6) and haemoglobin <10g/dL (OR 5.0; 95\% CIs 2.8-8.9). 30 day mortality was associated with inpatient status at the time of initial bleed (OR 3.3; 95\% CIs 2.0-5.4), age 60-79 (OR 3.3; 95\% CIs 1.5-7.1), age > 80 (OR 6.0; 95\% CIs 2.6-13.7), underlying liver disease (OR 7.2; 95\% CIs 2.9-17.7), hypotension (OR 2.9; 95\% CIs 1.5-5.3), and tachycardia (OR 2.1; 95\% CIs 1.3-3.6). No independent risk factors were identified for the requirement of surgery. Separate prognostic scoring systems (0-7) were created for rebleeding and mortality outcomes, with area under ROC curves 0.742 and 0.802 respectively. A score of 0 reflected a re-bleeding risk of $1.1 \%$ and 30 day mortality of $0.0 \%$, whereas a score of 6 reflected a re-bleeding risk and 30 day mortality risk of $50 \%$ in both scoring systems. No patients scored the highest risk grade of 7 in either model.
Conclusion These scoring systems can be used to calculate rebleeding risk and 30 day mortality in patients with LGIB. Further external validation and confirmation is required.

Disclosure of Interest None Declared

\section{PTU-036 ENDOSCOPIC MANAGEMENT OF MALIGNANT GASTRIC OUTLET OBSTRUCTION: RESULTS FROM A NEWLY CREATED REGIONAL CANCER SERVICE}

doi:10.1136/gutjnl-2013-304907.128

1,"D Ismail, ${ }^{2} \mathrm{~J}$ Deacon, 'B Macfarlane, ${ }^{2} \mathrm{D}$ L Morris, 'M Fullard, ${ }^{2} \mathrm{~S}$ Sargeant, ' $\mathrm{J}$ Evans, ${ }^{1}$ A Leahy. ${ }^{1}$ Department of Gastroenterology, West Hertfordshire Hospitals NHS Trust, ${ }^{2}$ Department of Gastroenterology, East and North Hertfordshire Hospitals NHS Trust, Watford, UK

Introduction Malignant gastric outlet obstruction can be a distressing medical condition leading to considerable morbidity with a well recognised poor prognosis. Previous studies (mostly outside of the UK) have shown that endoscopic insertion of a duodenal stent can alleviate the obstructive symptoms to good effect (1-3). In 2009 , we set up a regional service for duodenal stent insertion with an aim to replicate these results across a UK upper gastro-intestinal cancer network (catchment area 1.4 million).

Methods A retrospective analysis was performed in patients who had an endoscopically placed duodenal stent for inoperable cancer causing mechanical gastric outlet obstruction. We reviewed hospital/ endoscopy electronic records regarding patient demographics, length of hospital stay after the procedure, endoscopy re-intervention and survival.

Results Between July 2009 and November 2012 a total of 27 patients underwent duodenal stent (uncovered WallFlex ${ }^{\circledR}$, Boston Scientific) insertion. 15 were men, mean age of 70.6 years (range 27-86). 23/27 (85\%) patients were discharged home after the procedure, 2 were transferred to a hospice and 2 died in hospital. The average length of hospital stay after the procedure was 5.7 days (range 0-25).

Endoscopy re-intervention was performed in 2 patients for stent occlusion requiring further stent insertion. 22 patients have been followed until death with a mean survival period of 12.5 weeks (range 1-34). 5 patients remain alive at the time of abstract submission.

Conclusion Duodenal stent insertion offered a good palliative option in most of our patients. Our patient outcomes compared favourably to previous published studies.

Disclosure of Interest None Declared 